\title{
O ICMS ECOLÓGICO NO BIOMA AMAZÔNIA: UM INSTRUMENTO FISCAL (IN)EFICAZ PARA EFETIVAÇÃO DO PRINCÍPIO DO PROTETOR-RECEBEDOR
}

\author{
Luciano Costa Miguel $^{1}$ \\ Escola Superior Dom Helder Câmara (ESDHC)
}

Zayne Gil Brito de Souza Souto ${ }^{2}$

Escola Superior Dom Helder Câmara (ESDHC)

Artigo recebido em: 30/03/2020.

\section{Resumo}

Artigo aceito em: 10/07/2020.

O presente trabalho tem como objetivo apresentar o ICMS ecológico, investigando se suas principais características o tornam de fato um instrumento eficaz para a efetivação do princípio do protetor-recebedor, especialmente para o rico Bioma Amazônia. Com essa finalidade, serão estudados os conceitos propedêuticos que permeiam o tema, como o princípio do protetor-recebedor, a compensação por serviços ambientais e o próprio Imposto sobre a Circulação de Mercadorias e Serviços - ICMS. Em seguida, será verificado o sistema de repartição do referido imposto estadual, que tem o condáo de beneficiar os municípios que passarem a agir de maneira protecionista ao meio ambiente, bem como atuar como meio

de compensação por serviços ambientais. Ao fim, serão verificadas as experiências de 2 (dois) estados da nossa federaçáo que abrangem o bioma amazônico, a saber, Pará e Amazonas, com o fim de verificar se há políticas públicas tributárias que têm se aproveitado das potencialidades preservacionistas reveladas pelo ICMS ecológico. Para isso, será seguido o método de pesquisa hipotético-dedutivo, com foco no aspecto qualitativo e explicativo, por meio de coleta de dados bibliográfica e estudo de dois casos concretos.

Palavras-chave: compensação por serviços ambientais; experiência amazônica; ICMS ecológico; princípio do protetor-recebedor.

1Doutorando e mestre em Direito Ambiental pela ESDHC. Especialista em Direito Tributário pela Universidade Anhanguera Uniderp. Bacharel em Direito pela Pontifícia Universidade Católica de Minas Gerais (PUC-MINAS). Procurador da Fazenda Nacional. Professor de Direito Tributário da graduação da ESDHC e da pós-graduação em Direito Tributário do Centro de Estudos em Direito e Negócios (CEDIN) e da Faculdade Arnaldo/Pro Labore. ORCID: https://orcid.org/0000-0002-8565-944X / e-mail: lucianocmiguel@hotmail.com

2 Especialista em Direito Processual Civil pela Estácio de Sá/RJ. Graduada em Direito pela ESDHC. Advogada. E-mail: zaynegil@hotmail.com 


\section{ECOLOGICAL ICMS IN THE AMAZON BIOME: AN (IN) EFFICIENT FISCAL INSTRUMENT FOR EFFECTIVENING THE PROTECTOR-RECEIVER PRINCIPLE}

\section{Abstract}

The aim of this paper is to present the Ecological ICMS, investigating whether its main characteristics make it an effective instrument for the effectiveness of the protectorrecipient principle, especially for the rich Amazon biome. To this end, the propaedeutic concepts that permeate the theme will be studied, such as the protectorrecipient principle, compensation for environmental services and the Tax on the Circulation of Goods and Services - ICMS. Then, the system for allocating the aforementioned state tax will be verified, which has the power to benefit municipalities that start to act in a protectionist way to the environment, as well as to act as a form of compensation for environmental services. In the end, the experiences of 2 (two) states of our federation covering the Amazon biome, namely Pará and Amazonas, will be verified, in order to verify whether there are public tax policies that have taken advantage of the preservation potentialities revealed by the Ecological ICMS . For this, the hypothetical-deductive research method will be followed, focusing on the qualitative and explanatory aspect, through the collection of bibliographic data and the study of two concrete cases.

Keywords: Amazon experience; compensation for environmental services; ecological ICMS; protector-receiver principle. 


\section{Introdução}

Este artigo tem como intuito apresentar os principais elementos caracterizadores do Imposto sobre Operaçôes relativas à Circulação de Mercadorias e Prestação de Serviços de Transporte Interestadual e Intermunicipal e de Comunicação com finalidade ambiental (conhecido como ICMS ecológico) e demonstrar as razóes pelas quais ele se tornou um instrumento eficaz, ou não, de efetivação do princípio do protetor-recebedor na realidade brasileira, para tanto, vamos utilizar o caso do bioma Amazônia.

Como será verificado, o referido princípio do protetor-recebedor tem por objetivo compensar aquele que se priva de exercer atividades econômicas a favor de uma maior preservação do meio ambiente e promoção da saúde e da qualidade de vida de toda a coletividade.

A questão que se busca responder é se o ICMS ecológico tem se revelado um instrumento de concretização do princípio do protetor-recebedor ou tornou-se somente mais um instrumento ineficaz na busca de proteção ao meio ambiente. Para isso, optou-se pelo método de pesquisa hipotético-dedutivo, com foco no aspecto qualitativo e explicativo, por meio de coleta de dados bibliográficos e estudo de dois casos concretos.

Assim, pretende-se demonstrar que o ICMS ecológico tem sido na atualidade, um importante instrumento de fortalecimento do princípio ambiental aqui tratado, buscando, assim, de maneira preventiva, a preservaçáo do meio ambiente.

$\mathrm{O}$ tema do presente trabalho encontra-se situado no ponto de intersecção dos ramos do Direito Tributário, do Direito Financeiro e do Direito Ambiental. A relevância do tema se revela na necessidade em reconhecer as potencialidades de articular os princípios dos direitos tributário e financeiro para a proteção dos bens ambientais e, por conseguinte, da própria efetividade do Direito Ambiental. O direito tem a função de acompanhar e regular com eficácia as questóes mais atuais, e o ICMS ecológico é uma ferramenta legal ainda a ser implementada em alguns estados, e em evolução quanto a sua abrangência e resultados práticos.

$\mathrm{Na}$ atual sociedade de risco, tem-se observado a crescente necessidade de preservar o meio ambiente e o grande desafio tem sido justamente encontrar instrumentos eficazes de incentivo para essa preservação. Desse modo, o ICMS ecológico tem se revelado um grande aliado e guarda estreito vínculo com o princípio do protetor-recebedor, porquanto ambos têm como finalidade beneficiar aqueles agentes econômicos que preservam os sistemas e recursos naturais, obedecendo às regras estabelecidas por cada estado em suas respectivas leis.

É necessário estudar todos esses institutos de maneira conjunta, para que 
se possa induzir os agentes a alcançar a maior preservação ambiental possível, demonstrando, assim, que o protetor imediato, que se priva dos benefícios de exploraçáo do meio ambiente, pode e deve receber benefícios; no caso, um maior repasse do valor do ICMS destinado aos municípios.

Ao final do presente trabalho, serão verificadas as experiências de dois importantes estados brasileiros situados na região amazônica, a saber, Pará e Amazonas. Neste momento, será analisado se esses dois entes federativos têm efetivado este importante instrumento fiscal ou se há uma omissão quanto às políticas públicas tributárias de implementação do ICMS ecológico.

\section{0 princípio do protetor-recebedor e a compensação por serviços ambientais}

O princípio do protetor-recebedor estabelece que pessoas físicas ou jurídicas, responsáveis por melhores práticas ambientais, devem receber, de alguma maneira, uma compensaçáo, gratificação, prêmio ou pagamento, pois o fazem em benefício de toda a coletividade, porquanto o meio ambiente é bem de todos, sendo um direito fundamental usá-lo e gozá-lo de maneira ecologicamente equilibrada.

É importante que se reconheça que, geralmente, quem garante a proteção ambiental, o faz com alguns sacrifícios individuais a favor de toda a coletividade. De todo modo, o que se verificou ao se compulsar o tema, é que alguns autores colocam o princípio do protetor-recebedor como a antítese do princípio do poluidor-pagador, pois no primeiro, recebe-se por garantir a proteção ambiental e, no segundo, paga-se por poluir e degradar dentro dos limites permitidos.

Para Bechara (2010), contudo, o princípio do protetor-recebedor tem como finalidade tanto o desestímulo às práticas predatórias, quanto o incentivo às condutas preservacionistas, garantindo todo tipo de realização de benefícios ambientais.

Tal princípio teve sua positivação expressa no art. 6º, II, da Lei n. 12.305, de 2010, que trata da Política Nacional de Resíduos Sólidos. Foi também tratado, com grande importância, no Código Florestal (Lei n. 12.651, de 2012). Entretanto, o aludido princípio já existia e já era aplicado antes de sua previsão expressa.

Assim, fica claro que:

Este princípio visa remunerar todo aquele que, de uma forma ou de outra, deixou de explorar algum recurso natural em benefício do meio ambiente e/ou da coletividade, seja um agente público ou privado. Ao mesmo tempo serve como símbolo de justiça socioeconômica e ambiental, à medida que valoriza os serviços 
ambientais prestados, seguindo a lógica de que, se há valor econômico, é justo que se receba por ele (OLIVEIRA; SOUZA-LIMA, 2014, p. 92).

Observa-se, então, que, a partir do princípio do protetor-recebedor, não se pode continuar pensando somente no valor que os bens naturais têm para a exploração e produção, mas deve ser reconhecido o valor econômico dos bens naturais conservados, porquanto se trata de um direito da coletividade ao meio ambiente saudável e equilibrado e, aquele que o preserva em favor de toda a coletividade deve ser compensado por isso.

Assim, o referido princípio se relaciona estreitamente com a ideia de compensação por serviços ambientais. Em uma verdadeira crítica à sociedade atual, materializando uma profunda e pragmática análise da realidade vivida no mundo, segue arguta lição de Erika Bechara:

É bem verdade que, no melhor dos mundos, não seria preciso recorrer ao expediente compensatório-remuneratório para que as pessoas atuassem em prol dos serviços ambientais. No melhor dos mundos, elas fariam-no espontaneamente, sem nada receber em troca. Mas o melhor dos mundos nâo é aqui. Infelizmente a sociedade não atingiu grau de maturidade e consciência ambientalista que dispense instrumentos repressivos e instrumentos de incentivo. Some-se a isso o fato de que, para muitos, as florestas e a natureza em geral são sua fonte de renda ou o oposto, i.e, empecilhos à obtenção de renda. Logo, hoje, é preciso, sim, que a preservação da natureza não seja apenas um dever ético, mas também um bom "negócio" (BECHARA, 2010, p. 160).

A partir da análise de Bechara, nos elementos mais básicos do princípio do protetor-recebedor, é importante verificar como se dá a funcionalidade por meio da compensação por serviços ambientais.

A compensação, gratificação, premiação ou pagamento por serviços ambientais são mecanismos econômicos intimamente ligados ao princípio do protetor-recebedor, uma vez que atuam como instrumento de sua efetivação. Por isso, será apresentada uma visão geral da compensação por serviços ambientais e de como esta se relaciona com o ICMS ecológico.

Registre-se que serviços ambientais são aqueles prestados pelo próprio meio ambiente natural, como por exemplo, regulação de processos climáticos, controle de erosão, geração de oxigênio e manutenção da biodiversidade. Serviços estes que tornam a vida humana possível, saudável e equilibrada. 
Erika Bechara (2010, p. 158) cita quatro tipos específicos de serviços ambientais prestados pela natureza:

i) de provisão: fornecimento de bens naturais, como peixes, frutas, sementes, águas, madeiras, fibras vegetais etc. ii) de regulação: manutenção das chuvas, manutençâo da quantidade e qualidade das águas, regulação do clima etc. iii) de suporte: ciclagem de nutrientes, formação de solos, polinização, manutenção da biodiversidade etc. iv) culturais: manutenção das paisagens, das atividades educacionais e recreativas no ambiente natural etc.

Todavia, o próprio homem, um dos maiores beneficiários, pode e vem intervindo negativamente nessa prestação de serviços naturais. Em contrapartida, há diversas outras situaçôes, em que a sociedade pode e tem garantido ou otimizado sua execução.

Alguns agentes econômicos cuidarão de garantir a proteçáo da natureza por imposição legal, já outros o farão por livre espontânea vontade, ultrapassando a esfera de deveres legais. Nada mais justo que aqueles que têm práticas conservacionistas espontâneas sejam gratificados de alguma maneira. Remanesce, todavia, o debate se os que contribuem para a proteção ambiental de modo compulsório, ou seja, obedecendo às exigências legais, devem também receber algum pagamento por serviços ambientais.

A doutrina majoritária sustenta que, para fazer jus ao pagamento, as açóes protecionistas devem ir além da obrigação legal que a todos vincula: de proteger o ambiente de maneira individual, além de gerar um benefício que ultrapasse a esfera particular, gerando uma utilidade à coletividade. Este debate subsiste pelo fato de a obrigação de maior proteção ser exigência de apenas alguns agentes econômicos, como os proprietários de terra.

Em esclarecedora síntese, Daniela Roberta Slongo (2010, p. 179), coloca que

O sistema parte do princípio de que multar ou cobrar taxas de quem degrada o meio ambiente não é suficiente. Mais que isso, é necessário destinar recursos a quem garante a oferta de serviços ambientais, ou seja, pagar para quem preserva o meio ambiente.

Exemplos de compensaçôes por serviços ambientais pelo poder público no Brasil são o Bolsa Floresta (instituído pelo estado do Amazonas), a isenção de ITR para áreas das propriedades rurais cobertas de vegetaçáo protegidas e o próprio ICMS ecológico, já adotado por mais de dez estados.

Cabe ressaltar, contudo, que a compensação por serviços ambientais não tem que ser necessariamente de cunho financeiro. Deve-se a isso a preferência 
de alguns em adotar os conceitos de gratificação, premiação ou compensação no lugar de pagamento ou remuneração.

\begin{abstract}
Rubens Harry Born e Sergio Talocchi sugerem uma série de benefícios oferecidos ao responsável pela manutenção dos serviços ambientais, a saber: i) favorecimento na obtenção de créditos; ii) isenção de taxas e impostos; iii) aplicação (alocação) de receitas de impostos em programas especiais; iv) fornecimento preferencial de serviços públicos; v) disponibilização de tecnologia e capacitação técnica; vi) subsídios a produtos; vii) garantia de acesso a mercados ou programas especiais (BECHARA, 2010, p. 165).
\end{abstract}

Pode-se identificar, então, que a espécie de compensação utilizada no caso do ICMS ecológico é a citada no item três acima, pois se trata de uma espécie de redistribuição do imposto sobre operaçôes relativas à circulação de mercadorias e sobre prestaçóes de serviços de transporte interestadual, intermunicipal e de comunicação, beneficiando aqueles que têm práticas conservacionistas - tema que mais à frente será desenvolvido.

Quanto à legislação brasileira, não há ainda um instrumento único que regule a compensação por serviços ambientais, embora existam alguns projetos de lei em tramitação. Entretanto já existem algumas políticas públicas que utilizam este instrumento econômico dentro das especificidades de cada regiáo, adotando, assim, os diversos tipos de gratificação supraelencados.

Pode-se, ainda, mencionar outros importantes programas que se utilizam da compensação por serviços ambientais como o Proambiente (Programa de Desenvolvimento Socioambiental da Produçáo Familiar Rural) e o Mercado de Carbono. Além desses, a Lei do SNUC ${ }^{3}$ previu que aqueles que se beneficiam da proteção ao sistema hídrico, devem contribuir financeiramente, conforme regulamentação específica, para a proteção e a implementação das respectivas unidades de conservação.

Não somente no Brasil têm surgido políticas públicas que visam à aplicação da compensação. Em outros países do mundo, como Costa Rica, México, Bolívia, França e Estados Unidos há experiências com o pagamento por serviços ambientais que têm demonstrado que essa pode ser uma alternativa eficaz na busca do desenvolvimento com sustentabilidade.

Por fim, vale transcrever a síntese feita por Slongo (2010, p. 192-193) sobre o tema da compensaçáo por serviços ambientais:

3 SNUC é o Sistema Nacional das Unidades de Conservação. Sua lei é a de número 9.985 de 18 de julho de 2000. 
[...] minimizar os inúmeros riscos ambientais. Desta forma, faz-se necessário uma inversão da esfera punitiva para a esfera compensatória, por meio do princípio do protetor-recebedor que objetiva uma sanção positiva do Estado, permitindo a compensação por serviços ambientais prestados, sendo assim, uma forma de estímulo para os atores sociais, que têm sensibilidade ecológica e contribuem para a preservação/conservação do meio ambiente. Da mesma forma que a degradaçấo afeta a todos, a sua preservação também beneficia a coletividade. Sendo assim, há que considerar o pagamento por serviços ambientais como mais um dos eficientes instrumentos econômicos em prol da defesa ambiental.

Veja-se, portanto, o amplo reconhecimento que os instrumentos compensatórios recebem na preservação ambiental e no fortalecimento do vínculo de solidariedade que deve nortear a todos quando se trata da temática ambiental.

\section{Os elementos gerais do ICMS e o ICMS ecológico}

O ICMS é o imposto estadual que tem como materialidade a circulação de mercadorias e a prestação de serviços de transporte interestadual e intermunicipal e de comunicação. Encontra previsão na Constituição Federal de 1988 em seu art. $155, \mathrm{II}^{4}$, que estabelece que a competência de sua instituição é dos estados e do Distrito Federal.

O ICMS é o sucessor do antigo Imposto de Vendas e Consignações (IVC), tendo sido previsto pela reforma tributária veiculada pela Emenda Constitucional n. 18/65 e representa, atualmente, cerca de $80 \%$ da arrecadação dos Estados. Trata-se de exação tributária que recebeu em 1988 um significativo tratamento constitucional (art. 155, $\$ 2^{\circ}$, I ao XII).

A Constituição ainda prevê, em seu art. 146, III, $a$, que as normas gerais do ICMS e de todos os demais impostos devem estar previstas em Lei Complementar, com a finalidade de uniformizar o tratamento jurídico dessas exaçóes tributárias em âmbito nacional. Para isso, foi promulgada em 13 de setembro de 1996 a Lei Complementar n. 87, conhecida como Lei Kandir.

Já em seu art. 158, IV, o texto constitucional estabelece que 25\% do montante arrecadado com o ICMS de cada estado pertence aos seus respectivos municípios, sendo que, no parágrafo único desse mesmo artigo dispóe que até $1 / 4$ do

4 Art. 155. Compete aos Estados e ao Distrito Federal instituir impostos sobre: [...] II - operaçôes relativas à circulaçâo de mercadorias e sobre prestaçôes de serviços de transporte interestadual e intermunicipal e de comunicaçáo, ainda que as operaçôes e as prestaçôes se iniciem no exterior [...] (BRASIL, 1988). 
pertencente aos municípios será distribuído conforme lei estadual, ou lei federal, no caso dos territórios nacionais.

Quanto à repartição das receitas tributárias, esta é, em regra, matéria de Direito Financeiro, pois trata de relaçôes jurídicas entre os entes de Direito Público após o exaurimento das relaçóes de Direito Tributário. A forma federativa de Estado, em que a República Federativa do Brasil se constituiu, tornou necessária a criaçáo de um federalismo fiscal, baseado em um sistema constitucional de repartição de rendas, caracterizado primordialmente pela autonomia dos entes federados (com a atribuição de competência tributária própria), mas, também, pela participação dos entes menores na receita arrecadada pelos entes maiores.

Dessa maneira, quanto ao ICMS, os estados poderiam criar leis de modo a estabelecer critérios para repasse de $25 \%$ da parcela aos municípios, o que possibilitou a criação do chamado ICMS ecológico, que não é a criação de um novo imposto, mas, sim, um tipo de repartição das receitas tributárias, baseada em lei estadual e referente ao $1 / 4$ do imposto que pertence aos municípios, conforme permitido constitucionalmente.

Os estados da federaçáo, tendo como pioneiro o estado do Paraná em 1991, começaram a criar leis próprias de redistribuição do ICMS, obedecendo aos limites percentuais estabelecidos na Constituição. Tudo em busca de uma maior proteção ambiental por parte dos municípios e uma nova maneira de beneficiá-los, já que os municípios que contavam, por exemplo, com uma grande área de preservaçáo ambiental em seus limites territoriais, sofriam limitaçôes de uso do solo e, por consequência, apresentavam menor arrecadação de ICMS e por isso recebiam menor repasse, já que o critério era somente de que quem arrecadasse mais receberia maior valor.

Náo há dúvidas de que, no momento em que a Constituiçáo estabeleceu que, no mínimo $3 / 4$ da receita de ICMS a ser repartido entre os municípios seria creditado proporcionalmente ao valor adicionado nas operaçôes relativas à circulação de mercadorias e nas prestaçóes de serviços realizadas em seus respectivos territórios, o objetivo fora abastecer com mais recursos justamente os municípios que mais contribuíram com a arrecadação do referido tributo.

Do mesmo modo, Wilson Loureiro explica a necessidade sentida pelos municípios que preservavam o meio ambiente e, por consequência, recebiam menor repasse do ICMS, pois arrecadavam menos do tributo:

Os municípios sentiam suas economias combalidas pela restriçấo de uso causada pela necessidade de cuidar dos mananciais de abastecimento para municípios vizinhos e pela existência de unidades de conservaçấo, enquanto o Poder Público estadual sentia a 
necessidade de modernizar seus instrumentos de política pública (LOUREIRO, 2001).

Sobre isso, Scaff e Tupiassu (2005) recordam que o ICMS ecológico tem sua origem relacionada à busca de alternativas para o financiamento público em municípios, cujas restrições ao uso do solo constituem fortes empecilhos ao desenvolvimento de atividades econômicas clássicas. $\mathrm{O}$ instituto traz resultados surpreendentes capazes de conferir nova feição a todas as políticas ambientais nacionais.

Loureiro (2001) ainda reforça a ideia, afirmando que "nascido sob a égide da 'compensação', o ICMS ecológico evolui, transformando-se ao longo do tempo também em instrumento de incentivo, direto e indireto à conservação ambiental, hoje o que mais o caracteriza”. Assim, surge a ideia de pagamento por serviços ambientais, que a partir da noção de compensação do princípio do protetor-recebedor, traz um incentivo valioso para a proteção do meio ambiente.

Assim, o ICMS ecológico torna-se um instrumento de proteção ambiental, principalmente por efetivar os fundamentos do princípio do protetor-recebedor, por meio da compensação dos municípios que protegem o meio ambiente em seus limites territoriais.

Em outro trabalho, Priscilla Bonaparte (2005, p. 35) assevera, de maneira esclarecedora, que "assim, como instrumento de gestão Ambiental, o ICMS ecológico instala o critério ambiental na redistribuição do imposto, permitindo ao Estado influir no processo de desenvolvimento sustentável dos municípios".

Como afirmam Scaff e Tupiassu, surge aí uma ideia de "indução econômica" sendo possível uma interferência direta do Estado na administração dos municípios, isso porque a nova forma de repasse do ICMS influencia nas políticas públicas municipais (SACAFF; TUPIASSU, 2005). Portanto, é possível induzir os mais de 5.000 municípios brasileiros a preservar de maneira mais efetiva o ambiente natural, pois também buscam maior repasse de valores.

Cumaru (2008 apud HUPFFER; WEYERMÜLLER; WACLAWOVSKY, 2011, p. 108) ensina que o ICMS ecológico tem duas finalidades, sendo a primeira relacionada com a ideia de indução econômica, e a segunda, uma espécie de efetivação do princípio do protetor-recebedor:

1. Estimular a adoção pelos municípios de iniciativas de conservação ambiental e desenvolvimento sustentável, seja pela criaçấo de unidades de conservação, ou pela manutenção de áreas federais ou estaduais, seja pela incorporação de propostas que promovam o equilíbrio ecológico, a equidade social e o desenvolvimento econômico. 
2. Recompensar os municípios que possuem áreas protegidas em seus territórios e que, dessa forma, estâo impedidos de destinar a área para atividades produtivas tradicionais que poderiam gerar uma maior arrecadação e consequente participação na repartição do ICMS.

Reforçando a ideia de que o ICMS ecológico é, atualmente, uma relevante ferramenta em favor da preservação ao meio ambiente, Loureiro (2002) afirma que, nascido sob o argumento da compensação financeira aos municípios que apresentavam restrição do uso do solo em seus territórios para o desenvolvimento de atividades econômicas clássicas, o ICMS ecológico tinha tudo para se transformar numa ferramenta estéril, acrítica, uma espécie de "chancelador" puro e simples para o repasse dos recursos, mas felizmente foi, e está sendo possível transformá-lo em muito mais do que isto. Segundo esse autor, o ICMS ecológico tem representado um instrumento de compensaçáo, mas acima de tudo de incentivo, em alguns casos, e de contribuição complementar à conservação ambiental.

Importante registrar que o ICMS ecológico foi criado em alguns estados com objetivo ainda mais amplo que só uma gratificação aos municípios por preservarem áreas de unidades de conservação. Sobre isso, segue a abordagem de Slongo (2010, p. 181):

\footnotetext{
No estado de Minas Gerais, através do ICMS Ecológico criou-se incentivos econômicos para governos locais investirem em disposiçóes de resíduos sólidos e em estaçóes de tratamento de esgoto. Municípios que operem estaçóes de tratamento de esgoto para no mínimo 50\% e no máximo $70 \%$ de sua população urbana, com sistema adequado de disposição de resíduos sólidos, recebem uma parcela maior do ICMS. Esse incentivo econômico é combinado com o sistema de licenciamento: para obtê-lo os municípios precisam ter a licença ambiental das estaçôes de tratamento, usinas de compostagem ou aterros sanitários.
}

Faz-se necessário apenas demonstrar com alguns dados matemáticos que a realidade atual, por exemplo, no estado do Paraná, primeiro a criar o ICMS ecológico, é extremamente exitosa, pois também conforme Loureiro (2002), no caso paranaense, cabe realce de que entre 1992 e 2000 houve um incremento de $1.894,94 \%$ em superfície das unidades de conservação municipais, de 681,03\% nas unidades de conservação estaduais, $30,50 \%$ nas unidades de conservação federais e terras indígenas e de $100 \%$ em relação às RPPNs - Reserva Particular do Patrimônio Natural - estaduais. Houve, ainda, melhoria na qualidade da conservação dos parques municipais, estaduais e das RPPNs. 
Vistos os aspectos gerais do ICMS e do ICMS ecológico, é chegada a hora de se compulsar sobre a experiência de dois estados da federação que são abrangidos pelo bioma mais extenso e valioso do nosso país, com a finalidade de se investigar o que tem sido feito em relação ao ICMS ecológico para a preservação da floresta amazônica.

\section{A experiência na regiáo amazônica - o estado do Pará}

Conforme visto no tópico anterior, o ICMS transformou-se em uma ferramenta de grande valor para estimular a preservação dos sistemas ecológicos e compensar de alguma maneira os municípios que encontram claros limites para seu desenvolvimento econômico em razão da necessidade de preservação dos serviços e recursos naturais.

No Brasil, o art. 167, IV, da Constituição veda a vinculaçấo das receitas advindas de imposto. Apesar de não haver uma vinculação da aplicaçáo da cota,-parte do ICMS repassada aos municípios por meio do critério do ICMS ecológico devido ao disposto na Constituição, o ICMS ecológico atua como um mecanismo extrafiscal, buscando estimular os municípios a tomarem as atitudes desejadas, visando a recompensa financeira.

Sobre isso, Pozzetti e Campos (2017) consideram que, no Brasil, em matéria de meio ambiente não é possível o estabelecimento de impostos diretos; mas, dada a natureza das espécies tributárias, é possível a inclusão do tema Ecológico no campo do Direito Tributário, por meio da tributação extrafiscal realizada pela tributação indireta.

Doutra margem, importante registrar que o ICMS é um imposto de extrema importância arrecadatória no âmbito dos estados, assim como o é para os municípios por meio dos repasses constitucionais, os quais, conforme Pozzetti e Campos (2017), representam, em média, 90\% da receita tributária dos estados.

É também importante ressaltar que a utilização do ICMS ecológico, como critério de repasse do ICMS aos municípios, tem sido um estímulo às administraçôes locais para que invistam em áreas estratégicas visando aumentar seus percentuais. Isso afeta positivamente a qualidade de vida dos munícipes e do meio ambiente local. Assim, o ICMS ecológico tem funcionado como um mecanismo indutor e direcionador de açôes municipais, melhorando significativamente a vida local e a preservação do meio ambiente que é bem de todos.

Alguns dos critérios comumente utilizados são a quantidade de unidades 
de conservação, o tratamento de esgoto e resíduos, recuperaçôes de mananciais e critérios muitas vezes sociais, fugindo um pouco da visão meramente ambiental. Cada estado adotou critérios que melhor atendem a suas necessidades de investimento.

De todos os estados que tomaram a iniciativa de aderir à ideia do ICMS ecológico, o estado do Pará se destaca por ter adotado somente critérios ambientais e com um dos maiores percentuais distribuídos para esse fim. Conforme Merlin e Oliveira (2016), os demais estados dedicam cerca de 4,5\% dos valores de repasses aos municípios a critérios ecológicos, sendo que o estado do Pará tem o percentual de $8 \%$ para tais critérios, ficando atrás somente do estado do Tocantins que dedica $13 \%$. Com isso, verifica-se a dedicaçáo do estado do Pará em alcançar maior proteção de suas áreas verdes.

Vale, ainda, analisar mais detidamente os critérios utilizados pelo Pará em busca de maior preservaçáo do meio ambiente, já que a totalidade de seu território está dentro dos limites da Amazônia Legal e sua economia é em grande parte agroexportadora e extrativista de minérios.

Segundo Merlin e Oliveira (2016, p. 283), verifica-se que:

[...] o Pará desponta como um dos estados da Amazônia Legal com as maiores áreas desmatadas: cerca de 33,81\% do total desmatado na regiāo (IDESP, 2013a, p. 7). Além disso, a partir de 2006, o estado do Pará passou a ter a maior contribuição anual ao desmatamento da Amazônia, com 57\%, em 2009; 54\%, em 2010; e 47\%, em 2011 (BRASIL, 2013a, p. 57). Nunca um só estado registrou taxas tão altas de desmatamento, correspondentes a quase ou mais da metade das áreas desmatadas na Amazônia em um só período.

Nessa toada, havia a necessidade de criar meios de modificação da realidade apresentada no estado, surgindo entấo a Lei Estadual n. 7.638/2012, que teve os critérios fixados pelo Decreto n. 775/2013.

O estado em estudo repassa estes valores levando em consideração as unidades de conservação presentes em cada município, a redução do desmatamento, a área com cobertura vegetal e as áreas inseridas no Cadastro Ambiental Rural.

Explicando a distribuição dos valores, entre os critérios selecionados, Merlin e Oliveira (2016, p. 289) destacam que:

Note-se que o critério Unidades de Conservação passou a reger apenas $1 / 4$ do repasse ecológico, concedendo-se também $1 / 4$ para o critério de redução de desmatamento/cobertura vegetal e metade 
do valor repartido para áreas inseridas no Cadastro Ambiental Rural - CAR9. Trata-se de uma associação de elementos considerados relevantes pelo Estado para o alcance das metas de redução do desmatamento com as quais ele firmou compromisso.

Frise-se que a experiência no estado do Pará ainda é recente, tendo em vista que a Lei n. 7.638 daquele estado é de 2012 e ainda carece de algumas adaptações e estudos aprofundados para verificar a diminuição da degradação e aumento da proteção ambiental advindo dos incentivos do ICMS ecológico.

Segundo Merlin e Oliveira (2016), alguns municípios foram efetivamente recompensados pelos esforços, mas os resultados ainda não apareceram em razão da incompleta implementação do sistema de gestão ambiental, que apesar de encontrar as bases de suas estruturas no Decreto n. 775/2013, ainda não foi plenamente viabilizado. Nessa ordem de ideias, segundo os autores, no Estado do Pará o ICMS ecológico ainda necessita ser aperfeiçoado, como tem sido ao longo dos anos, mas já gerou alguns benefícios ao bioma da Amazônia.

Apesar de ainda apresentar graves problemas na implementação de seu sistema de gestão ambiental, inovaçôes bastante positivas - como a conjugação do critério reduçáo do desmatamento com a existência de cobertura vegetal mínima, a valorização do Cadastro Ambiental Rural (CAR) e a forma de ponderação no cômputo das Áreas Protegidas devem ser ressaltadas.

Vale, ainda, registrar o que afirmam Derani e Souza (2013), no sentido de que o sucesso do instrumento depende da boa administração dos recursos repassados pelo ICMS ecológico, devendo o município investir não apenas em obras públicas e sociais, mas em projetos ambientais que valorizem as áreas naturais protegidas, incluindo Reservas Privadas, como as RPPNs, e Unidades de Conservação pertencentes às três esferas federais, pelo que será financeiramente compensado, pois quanto melhor a qualidade da gestão ambiental municipal maior o índice de participaçáo nos recursos oriundos daquele imposto 5 .

Portanto, em que pese o desmatamento no estado do Pará ainda não ter se arrefecido, o ICMS ecológico já se revelou um mecanismo que, se bem implementado e acompanhado de um eficiente sistema de gestão ambiental, tem o potencial de estimular os municípios a sempre buscarem novas iniciativas preservacionistas para receber maiores repasses financeiros.

\footnotetext{
5 Um bom exemplo pode ser encontrado em São Miguel Arcanjo, no interior de São Paulo. O município tem, aproximadamente, 20\% de seu território ocupado por Unidades de Conservaçăo havendo recebido, entre os anos de 2006 a 2010, cerca de R\$ 2 milhóes a título de ICMS Ecológico, recurso aplicado em açóes de educação ambiental, na construçáo de novos pontos de coleta de lixo na zona rural, bem como na coleta seletiva da zona urbana, conforme estabelece a Lei Municipal n. 2.303/2000. Para outras informaçóes e exemplos, ver: http://www.icmsecologico.org. br. Acesso em 25 jun. 2020.
} 


\section{A não instituição do ICMS ecológico no estado do Amazonas}

No ano de 2019, foi notório o aumento dos danos causados na floresta amazônica por grandes incêndios, os quais, em sua imensa maioria, foram resultado de atividades humanas, entre elas, a devastação ambiental causada pelo crescente desmatamento na regiáo.

É necessário combater a degradação ambiental de todas as maneiras possíveis e criar métodos para amenizar a destruição ambiental que a cada dia tem mostrado suas consequências na vida dos seres humanos e dos demais seres vivos.

Dos estados brasileiros, o Amazonas é o que conta com a maior área da floresta amazônica, recebendo seu nome em virtude disso. Em razão da imensa área verde que deve ser preservada, muitos de seus municípios são extremamente isolados e não exercem grandes atividades econômicas que gerem recursos importantes para se desenvolverem. A dificuldade de acesso em muitos municípios por sua densa mata amazônica é algo que também restringe o desenvolvimento em várias localidades do estado e mantém as populaçôes em situaçôes até mesmo de precariedade.

A falta de meios para melhor desenvolvimento e a necessidade levam as pessoas que habitam essas áreas a explorar a mata de modo degradante e, muitas vezes, por valores ínfimos para enriquecimento de outros. A mata amazônica também tem sido imensamente desmatada para aumento das áreas de pasto e produção agrícola. Todas essas questôes atingem diretamente o estado do Amazonas.

Como dito, vários métodos devem ser usados para reprimir e diminuir os prejuízos causados ao maior bioma brasileiro. O ICMS ecológico tem se apresentado imensamente útil nos estados que o implantaram, sendo um mecanismo muito proveitoso e eficaz para a proteçáo ambiental e desenvolvimento dos municípios que inicialmente tinham seu crescimento econômico limitado por não poderem explorar a inteireza de seus recursos. Assim, este se apresenta como um aliado importante na preservação ambiental tendo, de certo modo, um viés compensatório.

É interessante enfatizar que o ICMS ecológico é simplesmente uma nova maneira de repartir os valores do ICMS que deve ser repassado aos municípios, sendo que os estados podem estabelecer os critérios para recebimento. Assim, não se trata de mecanismo de alta complexidade ou de difícil implantação, já que não se trata de nova tributação ou majoração.

Mesmo assim, na contramão da maioria dos estados brasileiros, o estado do Amazonas ainda não aderiu ao sistema de repasses que favorece a proteção 
ambiental e fatores sociais, mesmo apresentando muitas carências. Não há justificativas para tal omissáo legislativa, não somente pela importância de suas riquezas naturais, mas também pela questão socioeconômica, já que a criação do ICMS ecológico no Amazonas beneficiaria diretamente as dezenas de municípios abandonados do interior do estado, com o aumento de repasse do rico município de Manaus.

Aqui é importante frisar que Manaus, por ser simultaneamente a capital do Estado e o único polo industrial da Zona Franca de Manaus, -i uma arrecadação desproporcional de ICMS em relação ao restante do Estado, que representa cerca de $85 \%$ dos recursos, justamente por ser o município onde a quase totalidade de circulação de mercadorias e serviços de transporte e comunicação ocorre (CINCO..., 2019).

Vale pontuar que, segundo Tupiassu (2006), a redistribuição de receitas é algo totalmente previsto e inerente ao próprio funcionamento do ICMS ecológico. A finalidade ecológica desse instrumento tributário é, ao mesmo tempo, incentivar a preservaçáo ambiental e gerar recursos para preservar e recuperar áreas, criando emprego e renda, reduzindo, assim, a desigualdade regional.

A perspectiva é que a discussão ganhe força com o apoio da sociedade civil, para que o Amazonas abra espaço para a discussão sobre o ICMS ecológico, criando e regulamentando sua normativa para, assim, passar a fazer parte do rol dos estados que incentivam seus municípios para a boa gestáo ambiental de seus recursos naturais.

É de extrema necessidade que os legisladores e governantes do estado amazonense se mobilizem para implantar o ICMS ecológico e estabeleçam os critérios que melhor atendam à populaçáo do estado e à proteção ambiental, tendo em vista que o êxito alcançado em outros estados já é reconhecido há anos, como destaca Nieves (2014 apud POZZETTI; CAMPOS; 2017, p. 18):

O ICMS Ecológico foi reconhecido por diversas entidades e organismos como um instrumento de incentivo à conservação, chegando, inclusive, a receber premiação internacional. Em 1995, foi considerado pela Uniấo Internacional para a Conservação da Natureza e dos Recursos Naturais - IUCN, uma das sete experiências exitosas, para a conservaçấo da biodiversidade, na América Latina e no Caribe, pós Rio-92. Em 1996, foi considerado pela Fundação Getúlio Vargas, uma das cem experiências mais importantes em administração pública no Brasil. Ainda no mesmo ano, foi considerada pelo Ministério do Meio Ambiente, uma das cem experiências exitosas em gestão ambiental para 
o desenvolvimento sustentável, na Rio + 5. Um ano após, em 1997, ganhou o prêmio Henry Ford de Conservaçáo Ambiental, na Categoria "Negócios em Conservaçáo", organizado pela Conservação Internacional do Brasil - CI, com apoio da Ford do Brasil Ltda. Mais recentemente, em 2008, a edição de n o 2.077 da revista Veja promoveu o encontro de diversas personalidades para discutir e propor açóes para um Brasil melhor e, no rol de 40 prioridades totais, no tópico ambiental teve destaque o ICMS Ecológico como mecanismo de premiação às prefeituras pela preservação ambiental.

Como dito, é evidente a necessidade de estimular não somente a proteção ambiental, mas também levar garantias básicas e dignidade aos cidadãos moradores dos municípios mais afetados pelo impedimento de crescimento econômico que a preservação lhes impóe. Assim, a proteção ao meio ambiente agiria como um gerador de renda para esses municípios, possibilitando maiores investimentos em áreas que melhorariam a vida dos moradores locais.

Ressalta-se a conclusão de Pozzetti e Campos (2017), no sentido de que, na extrafiscalidade, os tributos deixam de ter uma função meramente arrecadatória para perseguir também um objetivo social, e que os exemplos de ICMS ecológico de vários estados brasileiros fortalece a criação deste no estado do Amazonas; sendo um mecanismo eficaz para gerar a sustentabilidade ambiental e econômica dos municípios amazonenses.

O estudo da Fundação SOS Mata Atlântica - ICMS ecológico e as Unidades de Conservação Municipais da Mata Atlântica, de 2019 apresentou dados que demonstram um crescimento de áreas de preservação decorrente da utilização de critérios ecológicos para redistribuição do ICMS em áreas de Mata Atlântica. O estudo (SOSMA, 2019, p. 56) considerou a partir dos dados levantados que houve um evidente salto no número e na representatividade das Unidades de Conservação municipais e no sistema de proteção nos estados e na Mata Atlântica, a partir da implementaçáo do ICMS ecológico.

Ante essas informaçóes, pode-se verificar que a não implementação do ICMS ecológico no estado do Amazonas representa uma clara inércia daquele ente federativo, pois trata-se de um importante mecanismo que já apresentou e apresenta grandes resultados nos estados que implementaram esses critérios. 


\section{Consideraçóes finais}

O presente trabalho abordou o estreito vínculo entre o ICMS ecológico e o princípio do protetor-recebedor, buscando investigar e questionar se a referida modalidade de imposto ambiental tem se revelado, de fato, um instrumento de efetivação do referido princípio e, por conseguinte, de promoção do direito fundamental ao meio ambiente ecologicamente equilibrado.

Com isso, foi levantada a hipótese questionando se o ICMS ecológico de fato tem se revelado um eficaz instrumento de proteção ambiental por meio da efetivação do princípio do protetor-recebedor, considerando-se seu sistema de repartição, que tem o condão de beneficiar os municípios modificassem o método de atuação com relação ao meio ambiente, atuando de maneira compensatória com os serviços ambientais. Assim, o ICMS ecológico alcança o objetivo principal do princípio do protetor-recebedor que é, por meio dessa compensaçáo por serviços ambientais, incentivar a proteção do meio ambiente. Sendo assim, pôde-se reafirmar a imagem do ICMS ecológico como verdadeiro instrumento de concretização do princípio do protetor-recebedor.

Ao se compulsar as experiências do estado do Pará, verifica-se que ainda há a premente necessidade de ampliaçáo e criação de mecanismos mais eficazes de proteção ambiental para que se faça bom uso e eficiente instrumentalização do ICMS ecológico. O problema naquele estado da federação não é legislativo, mas de gestão ambiental, de modo que o potencial ambiental do ICMS ali instituído possa ser plenamente aproveitado.

A despeito das experiências positivas com o ICMS ecológico em vários estados da federação, inclusive naqueles situados na Amazônia Legal, verificou-se que o estado do Amazonas ainda não implementou tal política tributária ambiental. Tal omissão, oriunda de um estado que conta com a maior reserva florestal, hídrica e de biodiversidade do país, revela-se injustificável e, como vimos, afeta não somente o meio ambiente, mas também o desenvolvimento socioeconômico dos demais municípios afastados da regiáo metropolitana de Manaus, ante o potencial caráter redistributivo dessa modalidade de ICMS ecológico.

Assim, o que se constata é que esse verdadeiro eldorado natural amazônico náo conta com uma política tributária adequada voltada para seu desenvolvimento sustentável, exigindo que o Estado brasileiro, em seus diferentes níveis, dependa demasiadamente dos demais instrumentos econômicos, e, sobretudo, de cada estrutura estatal de comando e controle para responsabilização dos agentes econômicos causadores de danos ambientais. 


\section{Referências}

AMADO, F. A. T. Direito ambiental esquematizado. 4. ed. São Paulo: Método, 2013.

BECHARA, E. A compensação e a gratificação por serviços ambientais na legislação brasileira. In: GALLI, A. (coord.). Direito Socioambiental. Curitiba: Juruá, 2010. p. 157-173.

BENJAMIN, A. H. Introdução ao direito ambiental brasileiro. In: SOARES JÚNIOR, J.; GALVÃO, F. (Coord.). Direito Ambiental na visão da magistratura e do Ministério Público. Belo Horizonte: Del Rey. 2003, p. 11.

BEZERRA, T. B. ICMS ecológico como instrumento de preservação ambiental: importância de sua implementação no estado do Amazonas. Revista Jus Navigandi, Teresina, ano 20, n. 4250, 19 fev. 2015. Disponível em: https://jus.com.br/artigos/34915. Acesso em: 25 jun. 2020.

BONAPARTE. P. O ICMS ecológico. Trabalho de Conclusão de Curso (Graduação em Direito) -Pontifícia Universidade Católica do Rio de Janeiro, Rio de Janeiro, 2005. Disponível em: http://www.maxwell.vrac.puc-rio.br/10135/10135. PDF. Acesso em: 25 jun. 2020.

BRASIL. Constituição (1988). Constituição da República Federativa do Brasil. Brasília, DF: Senado Federal, 2020. Disponível em: http://www.planalto.gov.br/ ccivil_03/constituicao/ConstituicaoCompilado.htm. Acesso em: 25 jun. 2020.

CINCO municípios do Amazonas concentram dinheiro federal e estadual. Amazonas Atual, 16 fev. 2019. Disponível em: https://amazonasatual.com.br/cinco-municipios-do-amazonas-concentram-dinheiro-federal-e-estadual/. Acesso em: 05 set. 2019.

DERANI, C.; SOUZA, K. S. S. Instrumentos econômicos na política nacional do meio ambiente: por uma economia ecológica. Veredas do Direito, Belo Horizonte, v. 10, n. 19, p. 247-265, set. 2013. Disponível em: http://www.domhelder.edu. br/revista/index.php/veredas/article/view/319. Acesso em: 26 jun. 2020.

HUPFFER, H. M.; WEYERMÜLLER, A. R.; WACLAWOVSKY, W. G. Uma análise sistêmica do princípio do protetor-recebedor na institucionalização de programas de compensação por serviços ambientais. Ambiente e Sociedade, São Paulo, v. 14, n. 1, p. 95-114, 2011. 
LACOMBE, M. M. Hermenêutica e argumentação: uma construção ao estudo do direito. Rio de Janeiro: Renovar, 2003.

LOUREIRO, W. ICMS ecológico: a consolidação de uma experiência brasileira de incentivo à conservação da biodiversidade. Ambiente Brasil, 10 out. 2001. Disponível em: https://ambientes.ambientebrasil.com.br/unidades_de_conservacao/ artigos_ucs/icms_ecologico_-_a_consolidacao_de_uma_experiencia_brasileira_ de_incentivo_a_conservacao_da_biodiversidade.html. Acesso em: 25 jun. 2020

LOUREIRO, W. Contribuição do ICMS Ecológico à conservação da biodiversidade no estado do Paraná. Tese (Doutorado em Ciências Florestais) - Universidade Federal do Paraná, Curitiba, 2002. Disponível em: http://www.floresta.ufpr.br/ pos-graduacao/seminarios/wilson/contribuicao_do_icms.pdf. Acesso em: 25 jun. 2020 .

MACHADO, P. A. L. Direito Ambiental brasileiro. 16. ed. São Paulo: Malheiros, 2007.

MERLIN, L. V. C. T.; OLIVEIRA, A. C. ICMS verde para a redução do desmatamento amazônico: estudo sobre uma experiência recente. Veredas do Direito, Belo Horizonte, v. 13, n. 25, p. 277-306, maio 2016. Disponível em: http://revista. domhelder.edu.br/index.php/veredas/article/view/595. Acesso em: 25 jun. 2020

OLIVEIRA, J. H. D.; SOUZA-LIMA, J. E. ICMS ecológico e princípio do protetor-recebedor: instrumentos para uma boa gestão ambiental. Revista Iniciação Científica CENSUMAR, Maringá, v. 16, n. 1, p. 91-97, jan./jun. 2014. Disponível em: http://periodicos.unicesumar.edu.br/index.php/iccesumar/article/ view/3477/2257. Acesso em: 25 jun. 2020.

ONU - ORGANIZAÇÃO DAS NAÇÕES UNIDAS. Declaração do Rio sobre meio ambiente e desenvolvimento. Rio de Janeiro, 1992. Disponível em: http:// www.onu.org.br/rio20/img/2012/01/rio92.pdf. Acesso em: 25 jun. 2020

PARÁ. Decreto n. 775, de 26 de junho de 2013. Regulamenta a Lei Estadual n. 7.638, de 12 de julho de 2012. Pará: Governo do Pará, 2013. Diário Oficial do Estado n. 32.426, 27 jun. 2013 Disponível em: https://www.semas.pa.gov. br/2013/06/27/d-e-c-r-e-t-o-no-775-de-26-de-junho-de-2013-publicado-nodoe-no-32-426-de-27062013/. Acesso em: 25 jun. 2020.

PARÁ. Lei Estadual n. 7.638/2012. Dispóe sobre o tratamento especial de que trata o $\$ 2^{\circ}$ do art. 225 da Constituição do Pará. Disponível em: https://www. semas.pa.gov.br/wp-content/uploads/2015/11/legislacao/estadual/Lei_Estadual_ no_7.638_ICMS_VERDE.pdf.. Acesso em: 25 jun. 2020. 
POZZETTI, V. C. P.; CAMPOS, J. F. ICMS Ecológico: um desafio à sustentabilidade econômico ambiental no Amazonas. Revista Jurídica UNICURITIBA, Curitiba, v. 02, n. 47, p. 251-276, 2017.

SCAFF, F. F; TUPIASSU, L. V. C. Tributação e políticas públicas: o ICMS ecológico. In: TÔRRES, H. T. (org.). Direito Tributário Ambiental. São Paulo: Malheiros, 2005. p. 724-748.

SLONGO, D. R. Consideraçóes gerais sobre o pagamento por serviços ambientais como um instrumento econômico para a conservação das águas, florestas e da biodiversidade. In: GALLI, A. (coord.). Direito socioambiental. Curitiba: Juruá, 2010. p. 175-195.

SOSMA - FUNDAÇÃO SOS MATA ATLÂNTICA. Valorização dos parques e reservas: ICMS ecológico e as unidades de conservação municipais da mata atlântica. 2019. Disponível em: https://www.sosma.org.br/wp-content/uploads/2019/07/ Ucs-municipaisdigital.pdf. Acesso em: 25 jun. 2020.

TUPIASSU, L. V. C. Tributação ambiental: a utilização de instrumentos econômicos e fiscais na implementação do direito ao meio ambiente saudável. Rio de Janeiro: Renovar, 2006. 